\title{
Gestão interfederativa do SUS: a experiência gerencial do Consórcio Intermunicipal do Sertão do Araripe de Pernambuco
}

\author{
Jadson Mendonça Galindo \\ Universidade Federal de Pernambuco (UFPE) \\ Joselma Cavalcanti Cordeiro \\ Faculdade de Ciências Médicas (UPE) \\ Renata Alves Gomes Villani \\ Secretaria Estadual de Saúde de Pernambuco (SES-PE) \\ Evandro Alves Barbosa Filho \\ Universidade Federal de Pernambuco (UFPE) \\ Cecile Soriano Rodrigues \\ Universidade de Pernambuco (UPE)
}

\begin{abstract}
O objetivo deste artigo foi analisar a experiência gerencial do Consórcio Intermunicipal de Saúde do Sertão do Araripe de Pernambuco (Cisape). Para isso, utilizou-se uma pesquisa qualitativa do tipo análise documental. Os documentos analisados foram relatórios produzidos por consultoria especializada, envolvida na implantação da gestão regionalizada e consorciada do Sistema Único de Saúde (SUS) em Pernambuco, no período de 2009 e 2010. Os resultados apontam que o Cisape adotou o modelo de gestão gerencialista, ou seja, orientado pela gestão pública pós-burocrática. A estrutura organizacional do Cisape foi definida como de direito público de natureza autárquica. A pesquisa identificou que em Pernambuco o Cisape se configurou como uma ferramenta importante para estimular a regionalização do SUS, porém com incipiente participação social.
\end{abstract}

Palavras-chave: gestão em saúde; consórcios públicos; política de saúde; gerencialismo; regionalização do SUS.

Gestión Interfederativa NHS: la experiencia de gestión del Consorcio Intermunicipal del Hinterland Araripe Pernambuco

El propósito de este artículo es analizar la experiencia de gestión del Consorcio Intermunicipal de Salud Hinterland Araripe Pernambucano (Cisape). Para ello, se utilizó una investigación cualitativa de tipo

DOI: http://dx.doi.org/10.1590/0034-76121478

Artigo recebido em 20 fev. 2013 e aceito em 24 jul. 2014.

Esse projeto de pesquisa contou com o apoio do CNPq Proc. n. 484335/2010-3. 
de documento de análisis. Los documentos fueron analizados los informes elaborados por consultores especializados, que participan en la aplicación de la gestión regionalizada y el consorcio del Sistema Único de Salud (SUS), en Pernambuco entre 2009 y 2010. Los resultados indican que la Cisape adoptó el modelo de gestión gerencial, es decir, impulsado por la gestión pública post-burocrático. La estructura organizativa de Cisape se definió como Ley Pública naturaleza autárquica. La investigación identificó que, en Pernambuco, la Cisape ha configurado como una herramienta importante para fomentar la regionalización del SUS, pero con la participación social incipiente.

Palabras clave: gestión de la salud; consorcios públicos; la política de salud; el gerencialismo; la regionalización del SUS.

Inter-federal SUS management: the managerial experience of the Inter-municipal Consortium of Pernambuco's Sertão do Araripe

The purpose of this article was to analyze the managerial experience of the Inter-municipal Consortium of Health of Pernambuco's Sertão do Araripe (Cisape). To do it, we used a qualitative research of document analysis. The documents analyzed were reports produced by specialist consultants, involved in the implementation of regionalized and consortium management of the Unified Health System (SUS) in Pernambuco from 2009 to 2010. The results indicate that Cisape adopted the model of managerial management, ie, driven by the post-bureaucratic public management. The organizational structure of Cisape was defined as Public Law of autarchic nature. The research identified that, in Pernambuco, Cisape has been set as an important tool to encourage SUS' regionalization, but with incipient social participation.

KEYWORDS: management in health; public consortia; health policy; management; regionalization of SUS.

\section{Introdução}

A Reforma Sanitária no Brasil ficou conhecida como um projeto de constituição e reformulação de um campo de saber, uma estratégia política e um processo de transformação institucional. Emergindo como parte da luta pela democracia, a reforma sanitária já ultrapassa três décadas, tendo alcançado a garantia constitucional do direito universal à saúde e a construção institucional do Sistema Único de Saúde (SUS) (Fleury, 2009). Embora essas conquistas sociais e políticas sejam significativas, o SUS ainda tem vários desafios. Entre eles, as pesquisas realizadas por Bravo (2012) e Ribeiro e Costa (2000) evidenciam que a descentralização e a regionalização desse sistema aparecem entre os principais desafios à sua materialização.

Nesse intuito, a Lei Orgânica da Saúde e as Normas Operacionais Básicas do Ministério da Saúde (Brasil, 1990a, 1993, 1996) definiram uma política de descentralização do sistema de saúde no Brasil fomentando um significativo incremento das atividades e da participação dos municípios na provisão de serviços de saúde (Neves e Ribeiro, 2006).

Entretanto, muitos municípios do Brasil enfrentam dificuldades na implementação do SUS. O subfinanciamento crônico, as dificuldades relativas aos recursos humanos, a dificuldade de acesso ao uso de tecnologia de diferentes níveis de complexidade e custo e a inexistência de estrutura física adequada, além da distância que dificulta o atendimento à saúde, são 
os limites mais comuns que levam os dirigentes municipais a procurar alternativas de gestão (Lima, 2000).

Neste contexto, os Consórcios Intermunicipais de Saúde (CIS) surgiram como uma alternativa de organização regional e cooperação federativa para melhoria do processo de gestão e de organização dos serviços de saúde (Ribeiro, 1994; Lima, 1998; Schineider, 2005; Nicoletto, Cordoni e Costa, 2005). Apresentam-se como uma prática de gestão inovadora no sistema de saúde no Brasil, que objetiva viabilizar o acesso da população a diferentes especialidades e serviços, de forma regionalizada e cooperada (Oliveira, 2008). O CIS é visto como uma associação entre entes federativos para a realização de atividades conjuntas, possibilitando a viabilização financeira de investimentos, e contribui para a otimização da rede de assistência, inclusive em relação à organização da referência, possibilitando melhor atendimento às necessidades de saúde das populações (Botti, 2010).

Neves e Ribeiro (2006), em estudo recente, apontam que 95\% dos municípios envolvidos em consórcios de saúde no Brasil têm menos de 50 mil habitantes, o que reforça a importância dos consórcios públicos como estratégia intergovernamental de municípios pequenos.

Embora seja tradicionalmente uma estratégia de gestão intermunicipal, em Pernambuco, a adoção dos consórcios públicos como estratégia de regionalização do SUS resultou de uma escolha do governo do estado. Além disso, diferente de outras experiências de consórcios na área da saúde, a formulação do Cisape como consórcio público é fundamentada no gerencialismo ou nova gestão pública que utiliza a racionalidade das organizações do mercado nas políticas e organizações públicas.

Tendo em vista que o modelo de gestão pública por meio de consórcios públicos foi adotado, seguindo esse mesmo alinhamento teórico, como estratégia operacional em todas as 12 Regiões de Saúde pelo governo do estado de Pernambuco para regionalizar essa política social, desde 2009, se faz necessário analisar criticamente esse modelo de gestão intergovernamental do SUS.

O objetivo deste artigo foi analisar a experiência gerencial do Consórcio Intermunicipal de Saúde do Sertão do Araripe Pernambucano. Porém, destacamos a necessidade de novos estudos que abordem diferentes aspectos dessa estratégia de gestão intergovernamental do SUS, em face da complexidade desse processo político-gerencial ainda em curso.

\section{Consórcios de Saúde no Brasil: origem e características}

A ideia de consorciamento para a provisão de serviços e ações públicas entre municípios já estava presente na Constituição Brasileira de 1937, que em seu art. 29 determinava que municípios da mesma região pudessem se coligar para a instalação, exploração e administração de serviços públicos comuns (Brasil, 1937).

No entanto, as experiências de consorciamento foram pouco expressivas até a Constituição Brasileira de 1988, que reconheceu o município como ente federativo, desencadeando um 
processo de intensa descentralização de políticas públicas, de atribuições e de responsabilidades. Na década de 1990, foi expressivo o crescimento no número de consórcios, mas, assim como as demais alternativas de cooperação intergovernamental, estes permanecem escassos no Brasil (Oliveira, 2008).

No âmbito público, o consorciamento foi desenvolvido inicialmente a partir de uma lógica semelhante, onde um grupo de entes federados, majoritariamente municípios, se associava de forma horizontal/cooperada e decidia agir de forma conjunta, sem fins lucrativos, para solucionar problemas comuns em determinada área. Esse arranjo de gestão era então denominado de consórcio administrativo e não era apto a assumir direitos ou contrair obrigações em nome de seus consorciados, não possuía personalidade jurídica e funcionava como mero protocolo de intenções (Simões, 2010).

Os consórcios públicos de saúde foram definidos por Rocha e Faria (2004) como a união ou associação de dois ou mais entes federados visando à resolução de problemas de gestão e prestação de serviços em uma região específica. Eles representam a busca de objetivos comuns, mediante a utilização cooperada de recursos humanos, planejamento regional coletivo e materiais disponíveis.

Em recente estudo, Sano (2010) identificou o atual panorama brasileiro do associativismo territorial em saúde, através de consórcios públicos. Segundo o autor, em 2009 o Brasil contava com 2.323 municípios consorciados; 867 municípios em consórcios públicos com participação do setor estadual e 623 municipalidades em consórcios públicos de saúde com participação federal. O estudo ainda afirma os resultados de pesquisas anteriores, que a saúde é a área com maior número de entes federados consorciados.

\section{Consórcios públicos de saúde em Pernambuco: uma escolha governamental}

Em 2007, o Governo do Estado de Pernambuco elaborou um modelo de planejamento e gestão denominado "Todos Por Pernambuco - Gestão Democrática e Regionalizada com Foco em Resultados". O objetivo desse modelo de gestão, ainda em curso, é organizar as iniciativas e atividades dos órgãos e secretarias de governo no intuito de subsidiar o gerenciamento, desde o diagnóstico até a avaliação das atividades (Pernambuco, 2009).

No documento "Todos por Pernambuco" foram eleitos dois focos prioritários das políticas e ações estaduais: os segmentos sociais mais vulneráveis da população e a consolidação e interiorização do desenvolvimento.

Neste plano, a política de saúde é reconhecida como estratégica para a gestão. Segundo o documento, o objetivo dessa política social é melhorar a atenção à saúde, com foco no atendimento integral (Pernambuco, 2009). E, tendo como prioridade a interiorização, mediante a regionalização dos serviços de saúde, o governo estadual optou pela regionalização por meio de consórcios públicos de direito público. 
O Governo do Estado de Pernambuco, por meio da Secretaria Estadual de Saúde, inicia a implementação de uma política de saúde estadual regionalizada, integrada e consorciada, buscando potencializar a capacidade de realizar as ações necessárias para o melhor atendimento à saúde para todas as populações espalhadas em todo o território - do litoral ao sertão. (Pernambuco, 2009:9)

O Governo do Estado de Pernambuco, no ano de 2008, assume como prioridade na gestão a interiorização através da implementação de uma política de saúde estadual regionalizada, integrada e consorciada buscando potencializar a capacidade de realizar as ações necessárias para a melhoria da saúde da população (Pernambuco, 2009).

Neste contexto, a Secretaria de Saúde de Pernambuco, por meio da Portaria no 817, de 15 de setembro de 2009, aborda: a instituição de grupos de trabalho, definição de objetivos e prazos estabelecidos para a efetivação do processo de regionalização da saúde no estado de Pernambuco. Entre os objetivos da gestão presentes no documento, está o de conhecer experiências exitosas de regionalização em saúde por meio de consórcios públicos de outros estados brasileiros: Ceará, Paraná e Minas Gerais (Pernambuco, 2009).

Pernambuco apresenta experiências de consórcios intermunicipais de saúde anteriores ao Cisape. Mas a política governamental de incentivo à regionalização consorciada, iniciada em 2009, é resultado da atual gestão no Governo do Estado. Nesta, a política de saúde foi abordada sob novas diretrizes e utilizando novos modelos e tecnologias de gestão pública (Pernambuco, 2009).

Na atualidade, Pernambuco possui oito consórcios públicos formados, quatro já estando regulamentados, e o Cisape é o projeto piloto, pois foi o primeiro a ser regulamentado e a instalar o seu Núcleo Intermunicipal de Saúde (NIS), que tem a função de gerir de forma intergovernamental e participativa a saúde na Região do Araripe (Pernambuco, 2009). Além do Cisape, o Consórcio dos Municípios da Mata Norte e Agreste Setentrional (Comanas) já iniciou as atividades do seu NIS.

Em relação ao modelo de gestão pública adotada pelo Cisape, os relatórios oriundos das atividades de implementação da gestão consorciada no Sertão do Araripe evidenciam que o marco teórico-metodológico que orienta a constituição dos consórcios públicos de saúde em Pernambuco é o da nova administração pública ou gerencialismo:

A evolução dos estudos e o processo natural de adaptação a novas realidades trouxeram uma nova forma de fazer gestão pública, denominada por Osório (2003) de nova gestão pública. Em meados da década de 1970, a reforma da administração pública se tornou uma palavra de ordem em quase todo mundo. Esta foi baseada no modelo de gestão privado, introduzindo uma lógica de redução dos custos, do aumento da eficiência e da produtividade, da flexibilidade administrativa e do controle de resultados, com a finalidade de transformar o Estado em uma organização mais ágil, descentralizada e adequada às demandas atuais e futuras da sociedade, oferecendo serviços de qualidade e centrados no cidadão (Osório, 2003 apud Iaupe, 2010a:19). 
Para Farah (2010) a agenda de mudanças das políticas e da administração pública, embora não tenha se desvencilhado do componente democrático, recebeu assim mesmo alterações, enfatizando o fator de uma gestão e busca da eficiência.

Este direcionamento da gestão estadual, em consonância com o Decreto Federal no 7.508, de junho de 2011, sinaliza que o planejamento de saúde no âmbito estadual seja realizado de maneira regionalizada, a partir das peculiaridades municipais (Brasil, 2011).

Diante da emergência de novos modelos de gestão e execução da política de saúde, é necessário analisar a expansão dos consórcios públicos de saúde. Pois as desigualdades no acesso/utilização dos serviços de saúde também têm uma face loco-regional e, ao contrário do que ocorre em outros países capitalistas que possuem sistemas universais de saúde, no Brasil os serviços privados de saúde, grande parte deles inseridos na rede complementar do SUS, operam com total liberdade em relação a sua localização geográfica. O que ocasiona a concentração de equipamentos e recursos humanos em regiões e estados mais ricos, em detrimento das áreas onde seriam mais necessários (Ipea, 2010).

Mas como será analisado no próximo tópico, as transformações nos modelos de gestão da política de saúde são determinadas por um conjunto de debates políticos e ideológicos mais amplos, no seio do qual o discurso reformador e welfarista do SUS é questionado por discursos gerencialistas, fundamentados na racionalidade do mercado.

\section{Adoção de novos modelos de gestão e do gerencialismo: tendências contemporâneas da política de saúde}

Os conflitos relacionados aos novos modelos de gestão do SUS são intensos. Paim e Teixeira (2007) defendem o argumento, contrário ao discurso da reforma neoliberal, que para publicizar o SUS sem privatizá-lo seria necessário torná-lo menos público, estatal.

A busca de alternativas para uma nova institucionalidade do SUS passa pela necessidade de garantir o seu caráter público e não, necessariamente, pela sua subordinação à chamada "administração direta do Estado", protegendo-o da descontinuidade administrativa e de intercorrências derivadas de manobras da política partidária. (Paim e Teixeira, 2007:18)

Para os defensores das parcerias público-privadas como forma de materializar o SUS, é necessário que o sistema nacional de saúde utilize estratégias intermediárias que mantenham o caráter público e entidades não estatais gestoras e/ou provedoras de serviços. Para eles, um dos grandes problemas do SUS, resultante do processo de Reforma Sanitária, é o fato de a gestão ocorrer exclusivamente por meio dos governos, sendo, portanto, utilizadas como instrumento político (Paim e Teixeira, 2007). Nesse sentido, eles apontam os consórcios públicos como elemento da administração pública direta, fundamentais à eficiente institucionalização do SUS (Batista, 2011; Paim e Teixeira, 2007). 
No Brasil, diversos sujeitos políticos e intelectuais têm defendido a expansão da abertura dos serviços de saúde à iniciativa privada e a substituição do modelo democrático-democrático pelo gerencialista (Neves, 2007). Segundo essa perspectiva, emergente na agenda da política de saúde, cabe ao Estado permanecer como formulador da política pública, mas a gestão/execução deve ser repassada total ou parcialmente às organizações não estatais, como as Santas Casas de Misericórdia, que por sua finalidade são consideradas entidades públicas não estatais, como os consórcios públicos (Ibañez e Vecina Netto, 2007; Paim e Teixeira, 2007).

Esse tipo de contrato entre diferentes níveis do Estado e o agente público não estatal, consórcio público de saúde, refere-se à necessidade de materializar a dimensão sistêmica do SUS, a fim de evitar que a desarticulação, desintegração e atomização, hoje existentes, de municípios e/ou estados isolados na gestão/provisão de serviços de saúde sejam aprofundadas. Nesse sentido, esse modelo de gestão pode se associar a outros instrumentos e políticas gerenciais de nível local, regional e federal para assegurar a integração e a articulação da rede de serviços e ações de saúde, bem como o acesso regionalizado da população (Batista, 2011; Ibañez e Vecina Netto, 2007; Ribeiro, 2007).

Os variados modelos de gestão vivenciados pelo SUS, inclusive o CIS, são profundamente influenciados por distintos referenciais teóricos na área da gestão pública e marcados por projetos políticos em disputa. Analisando o contexto histórico brasileiro recente, Paula (2005) identificou dois influentes modelos de gestão pública.

O primeiro, inspirado na vertente gerencial, foi efetivamente implantado na década de 1990, durante o governo do ex-presidente Fernando Henrique Cardoso. O modelo gerencialista ou da nova gestão pública propôs a reforma gerencial do Estado baseado na crítica ao patrimonialismo e autoritarismo, enfatizando a profissionalização e o uso de práticas gerenciais do setor privado (Paula, 2005). Esse modelo representou as novas pressões do capitalismo sobre a gestão das políticas públicas, especialmente das sociais (Andrews, 2010).

Nesse período, o modelo gerencial teve o suporte de recomendações da Reforma do Estado, apoiado em emenda constitucional, que reestruturou as atividades estatais em dois tipos: a) as "atividades exclusivas" do Estado: a legislação, a regulação, a fiscalização, o fomento e a formulação de políticas públicas; b) as "atividades não exclusivas" do Estado: os serviços de caráter competitivo e as atividades auxiliares ou de apoio. No âmbito das atividades de caráter competitivo estão os serviços sociais (saúde, educação, assistência social) e científicos, que seriam prestados tanto pela iniciativa privada como pelas organizações sociais que integrariam o setor público não estatal. As atividades de apoio, como limpeza, vigilância, transporte, manutenção, entre outras, seriam submetidas à licitação pública e contratadas como terceiros (Paula, 2005).

O segundo modelo, ainda em desenvolvimento, mas profundamente questionado pela hegemonia do modelo gerencialista, tem como principal referencial a vertente societal, ligada à tradição mobilizatória brasileira, possuindo raízes nos ideais da teologia da libertação, na educação popular e nas experiências dos movimentos populares e sindicais. Experiências efe- 
tivas sob inspiração societal vêm ocorrendo em especial com a participação popular na gestão pública por meio de conselhos gestores tripartites e orçamento participativo. No cerne desse modelo está a ampliação da participação de atores sociais na agenda das políticas públicas (Paula, 2005).

Para Paula (2005) e Andrews (2010), na vertente gerencial, a ênfase recai principalmente nas dimensões econômico-financeira e institucional-administrativa. Na vertente societal, a ênfase é na dimensão sociopolítica. A vertente gerencial, que está imbricada com o projeto político do ajuste estrutural e do gerencialismo, baseia-se nas recomendações dessas correntes para reorganizar o aparelho do Estado e reestruturar a sua gestão, focalizando as questões administrativas. A vertente societal, por sua vez, enfatiza principalmente a participação social e procura estruturar um projeto político que repense o modelo de desenvolvimento brasileiro, a estrutura do aparelho de Estado e o paradigma de gestão.

\section{Métodos e técnicas da pesquisa: a busca das especificidades da gestão consorciada em Pernambuco}

Esta é uma pesquisa do tipo qualitativa. Para a análise do material da pesquisa utilizou-se a análise documental. Essa é uma operação ou um conjunto de operações que objetivam representar o conteúdo de um documento diferentemente do original, com o intuito de facilitar sua consulta e referenciação. Desta forma, a técnica de análise documental tem por objetivo dar forma conveniente e representar de outro modo a informação contida nos documentos originais, por intermédio de procedimentos de transformação (Bardin, 2011).

O propósito a atingir é o armazenamento sob uma forma variável e a facilitação do acesso ao observador, de tal forma que se obtenha o máximo de informação, com o máximo de pertinência. A análise documental permite passar de um documento primário (bruto) para um documento secundário, que seja uma representação do primeiro (Bardin, 2011).

Para Yin (2005), pesquisas científicas que publicizem o conteúdo de documentos podem garantir o acesso a informações relevantes principalmente quando as evidências documentais são fragilizadas pela dificuldade e/ou negação de acesso aos arquivos institucionais, pois, quando perdidas, sua recuperação pode ser baixa.

Para este estudo foram analisados, primordialmente, os relatórios referentes às atividades realizadas para implantação da gestão regionalizada e consorciada do SUS em Pernambuco, no período de 2009 e 2011. Os dados secundários foram solicitados ao Instituto de Apoio à Universidade de Pernambuco (Iaupe), responsável pela consultoria especializada prestada ao estado no processo de implantação da gestão consorciada da saúde, e encontram-se registrados em arquivo da instituição.

Os documentos analisados compõem um acervo registrado sob o título comum de Relatórios da Gestão Regionalizada, Consorciada e Integrada da Saúde Pública no Estado de Pernambuco e estão divididos em nove volumes com pouco mais de 650 páginas, conforme o quadro 1. 
Quadro 1

Documentos arquivados no laupe, referentes à consultoria sobre Consórcio Intermunicipal de Saúde em Pernambuco

\begin{tabular}{|c|c|}
\hline Relatório & Ementa \\
\hline (laupe, 2009a). Carta laupe - Proposta de Trabalho & $\begin{array}{l}\text { Consultoria para planejamento, organização, instalação e } \\
\text { implementação de uma gestão regionalizada, consorciada e integrada } \\
\text { da saúde pública no Estado de Pernambuco. }\end{array}$ \\
\hline $\begin{array}{l}\text { (laupe, 2009b). Projeto (re) estruturador da } \\
\text { regionalização em saúde do estado de Pernambuco. }\end{array}$ & Oficinas regionais para construção de consensos da regionalização. \\
\hline (laupe, 2010a). Primeira Etapa - Primeira fase & Planejamento e organização dos trabalhos de consultoria. \\
\hline (laupe, 2010b). Primeira Etapa - Segunda fase & $\begin{array}{l}\text { Produção de documentos técnicos e jurídicos para constituição e } \\
\text { instalação dos consórcios. }\end{array}$ \\
\hline (laupe, 2010c). Primeira Etapa - Terceira fase & $\begin{array}{l}\text { Instrumentalização técnica para elaboração do planejamento } \\
\text { estratégico das secretarias de saúde dos municípios consorciados. }\end{array}$ \\
\hline (laupe, 2010d). Primeira Etapa - Quarta fase & Constituição e instalação de consórcios. \\
\hline (laupe, 2010e). Primeira Etapa - Quinta fase & Planejamento estratégico e estrutura organizacional do consórcio. \\
\hline (laupe, 2010f). Primeira Etapa - Sexta fase & Planejamento estratégico e estruturação organizacional do NIS. \\
\hline (laupe, 2010g). Primeira Etapa - Sétima fase & $\begin{array}{l}\text { Acompanhamento, controle e avaliação dos resultados do consórcio e } \\
\text { do NIS. }\end{array}$ \\
\hline
\end{tabular}

Fonte: laupe (2009a, 2009b, 2010a-g).

Os documentos foram selecionados por apresentarem um registro direto e mais completo sobre a experiência recente dos consórcios públicos no estado de Pernambuco e por conterem informações pertinentes aos objetivos deste estudo.

A partir da análise documental sobre o Cisape foram elaboradas as seguintes categorias temáticas: (i) Constituição do Cisape; (ii) Modelo de Gestão; (iii) Estrutura organizacional; (iv) Contrato de Programa e Contrato de Rateio; (v) Gestão Financeira; (vi) Controle Social; (vii) Gestão de Pessoas do Consórcio.

Este artigo foi desenvolvido por um grupo de pesquisa "PRAXIS: política, planejamento e gestão em Saúde" do Núcleo Integrado de Saúde Coletiva (Nisc/UPE) como trabalho de conclusão de curso de residência em saúde coletiva.

A pesquisa cumpriu as determinações da Resolução no 196, de 10 de outubro de 1996, do Conselho Nacional de Saúde, obteve anuência do Iaupe e foi aprovada pelo Comitê de Ética da Universidade de Pernambuco, sob o Parecer nº 012/2010. 


\section{Analisando os resultados da pesquisa}

\section{1 Constituição do Cisape}

O Cisape foi criado em 2005. Mas a sua adequação à nova legislação sobre consórcios públicos ocorreu em 14 de janeiro de 2008 com a participação de 13 municípios-membros, localizados no Sertão do Araripe, Sertão do São Francisco e Sertão Central, que estão distribuídos nas Gerências Regionais de Saúde (Geres) VIII e IX do estado, conforme quadro 2 (Iaupe, 2010d).

$$
\text { Quadro } 2
$$

Distribuição da população dos municípios integrantes do Cisape por região de desenvolvimento e Geres, Pernambuco

\begin{tabular}{|cccc|}
\hline REGIÃO DE DESENVOLVIMENTO & MUNICÍPIO & GERES & POPULAÇÃO \\
\hline & Araripina & IX & 77.363 \\
\cline { 2 - 4 } & Bodocó & IX & 35.178 \\
\cline { 2 - 4 } & Exu & IX & 31.636 \\
\cline { 2 - 4 } & Granito & IX & 6.857 \\
\cline { 2 - 4 } SERTÃo DO ARARIPE & Ipubi & IX & 28.120 \\
\cline { 2 - 4 } & Moreilândia & IX & 11.137 \\
\cline { 2 - 4 } & Ouricuri & IX & 64.335 \\
\cline { 2 - 4 } & Santa Cruz & IX & 13.594 \\
\cline { 2 - 4 } & Santa Filomena & IX & 13.322 \\
\hline SERTÃO DO SÃO FRANCISCO & Trindade & IX & 17.116 \\
\hline SERTÃO CENTRAL & Dormentes & VIII & 16.915 \\
\hline TOTAL & Parnamirim & IX & 20.227 \\
\hline & 13 MUNICÍPIOS & & 362.388 \\
\hline
\end{tabular}

Fonte: Relatório da Gestão Regionalizada, Consorciada e Integrada da Saúde Pública no Estado de Pernambuco/Governo do Estado de Pernambuco (2010).

Para constituir um Consórcio, a Lei no 11.107, de 6 de abril de 2005, estabelece a obrigatoriedade da criação de uma pessoa jurídica, para que possa assumir direitos e obrigações. A personalidade jurídica pode ser de direito público ou de direito privado. Essa lei foi regulamentada mais tarde pelo Decreto oㅡ 6.017, de 17 de janeiro de 2007 (Brasil, 2007).

No caso do Cisape, foi definida como de direito público, pois se apresenta como uma associação pública, de natureza autárquica, do tipo multifinalitário, integrante da administração indireta e obedece a todos os princípios da administração pública (Iaupe, 2010d).

A associação com os municípios vem ocorrendo de forma horizontal, pois são constituídos por entes da mesma esfera de governo, no caso, município-município. De acordo com o 
relatório Iaupe (2010b) o estado participa desse consórcio como cooperador técnico-profissional e financiador.

Estrutura semelhante foi encontrada por Neves e Ribeiro (2006), quando analisando o CIS mais antigo do setor saúde no Brasil, na região de Penápolis, ao identificarem o início da associação entre municípios e outros entes federativos.

O projeto inicial de implantação dos consórcios intermunicipais de saúde em Pernambuco previa a implantação de nove consórcios (Iaupe, 2009a). O primeiro destes consórcios foi implantado no Sertão do Araripe Pernambucano, por apresentar os piores indicadores de saúde do estado (Iaupe, 2009a). Além disso, um estudo realizado pela Secretaria de Planejamento e Gestão do Estado de Pernambuco, para a construção do Plano de Governo Todos por Pernambuco, indicou que a principal reclamação da população do Sertão do Araripe estava relacionada aos serviços de saúde existentes na região (Pernambuco, 2009).

\subsection{Modelo de gestão do Cisape}

Os consórcios intermunicipais foram implantados no estado de Pernambuco sob um cenário político de transição de governo e de modelo de gestão. Em 2008, o Governo do Estado de Pernambuco apresentou seu plano político de gestão denominado Todos por Pernambuco - Gestão Democrática e Regionalizada com Foco em Resultados. Esse plano é uma proposta de gestão pública que traz para os espaços e instituições governamentais as práticas de gestão empregadas no meio empresarial, denominadas gerencialistas ou pós-burocráticas (Iaupe, 2010f).

A administração pública gerencial emergiu, na segunda metade do século $\mathrm{XX}$, como resposta à crise do Estado; como modo de enfrentar a crise fiscal; como estratégia para reduzir o custo e tornar mais eficiente a administração dos imensos serviços que cabiam ao Estado; e como um instrumento para proteger o patrimônio público contra os interesses do rent-seeking ou da corrupção aberta. Mais especificamente, desde a década dos 1960 ou, pelo menos, desde o início da década dos 1970, crescia uma insatisfação, amplamente disseminada, em relação à administração pública burocrática (Bresser-Pereira e Spink, 1998).

Bresser-Pereira e Spink, em 1998, definiram a administração pública gerencial como orientada para o cidadão e para a obtenção de resultados; pressupõem que os políticos e os funcionários públicos são merecedores de um grau limitado de confiança; como estratégia, servem-se da descentralização e do incentivo à criatividade e à inovação; o instrumento mediante o qual se faz o controle sobre os gestores públicos é o contrato de gestão.

É interessante pontuar que o planejamento, organização, instalação e implementação do consórcio público intermunicipal do Araripe são resultado da iniciativa da Secretaria Estadual de Saúde de Pernambuco para estimular o processo de planejamento local e a regionalização no estado (Iaupe, 2010f).

A implantação dessa política de gestão foi acompanhada por consultoria especializada do Iaupe (2010a). Os registros documentais evidenciam que o tipo de consultoria prestada 
foi a "por processo". A opção por essa natureza de consultoria demandou dos consultores a participação, envolvimento e engajamento em todas as etapas da regionalização por consórcios públicos em Pernambuco, o que se deu mediante a realização de atividades reunindo todos os atores diretamente envolvidos com a regionalização consorciada em Pernambuco (Iaupe, 2010d).

De acordo com a proposta de trabalho aprovada pela Secretaria de Saúde de Pernambuco, a gestão regionalizada consorciada possibilitou viabilização financeira de investimento, contribuindo para a superação de desafios locais na implementação do SUS de forma eficaz, eficiente, com foco em resultados, conforme o plano de gestão do estado (Iaupe, 2010f). "A gestão do Governo do Estado de Pernambuco buscou, desde o seu início, implementar uma gestão pública focada em planejamento e gestão para alcance dos resultados propostos" (Iaupe, 2010f:13).

A vertente gerencial, que está imbricada com o projeto político do ajuste estrutural e do gerencialismo, se fundamenta nas recomendações dessas correntes para reorganizar o aparelho do Estado e reestruturar a sua gestão, focalizando as questões administrativas (Paula, 2005).

Dessa forma, segundo Viana e colaboradores (2011), o estado de Pernambuco assume um papel centralizador que se posiciona na terceira fase, que se caracteriza por um novo desenvolvimentismo e novo papel do estado. Segundo a autora, esse contexto de transição significa mudança na condução política brasileira de saúde, considerando-se a saúde sob duas dimensões conflitantes: a acumulação de capital e a de proteção social.

Destaca-se nesse cenário a relação entre o Cisape e outro modelo de gestão paraestatal implantado em Pernambuco, a Organização Social (OS). Em outubro de 2010, o Cisape contratou a Organização Social Santa Casa de Misericórdia do Recife para dirigir o Hospital Regional Fernando Bezerra, que estava sob gestão do Cisape, desde maio de 2010, sendo função do Cisape monitorar as metas contratualizadas entre ele e a OS (Iaupe, 2010f).

\subsection{Estrutura organizacional do Cisape}

Para a operacionalização do Consórcio do Araripe pernambucano foi necessária a estruturação organizacional que é composta por: Assembleia Geral, Diretoria Executiva e Núcleos de Gestão (Iaupe, 2010d).

A Assembleia Geral corresponde à instância máxima, composta por todos os prefeitos dos 13 entes federeados consorciados, reunindo-se bimestralmente. É de competência da Assembleia Geral a decisão sobre reformas do contrato do consórcio, no estatuto, assim como eleger, empossar e destituir a Diretoria Executiva (Iaupe, 2010d).

A Diretoria Executiva do Cisape é composta por cinco membros, sendo: presidente, vice-presidente, secretário-geral, primeiro e segundo tesoureiros. A responsabilidade da Diretoria Executiva é administrar o consórcio (Iaupe, 2010d). 
Secretaria Executiva do Cisape é o setor de articulação, integração e execução das ações propostas, e iniciará sua atuação composta de um secretário executivo.

O perfil do funcionário que assumiu a Secretaria Executiva foi definido anteriormente entre os entes consorciados, conforme o relatório (Iaupe, 2010c) em reunião de assessoramento técnico para elaboração do planejamento estratégico das secretarias municipais de saúde da regionalização.

O perfil do secretário executivo deve ser: nível superior, de reconhecida e comprovada capacidade técnica, probidade, integridade, dignidade, respeitabilidade, que não seja filiado a partidos políticos, sendo livremente indicado pelo Presidente e referendado pela Assembleia Geral, por pelo menos 2/3 dos seus membros. (Iaupe, 2010c:37)

A Secretaria Executiva do Cisape tem como principais atribuições: organizar a Secretaria Executiva, elaborar programas técnicos de desenvolvimento e orientar sua execução, contribuir para a pauta de assuntos e os trabalhos das reuniões da Assembleia Geral, ter sob sua guarda e responsabilidade os bens do Cisape, administrar e comandar o pessoal da Secretaria Executiva e dos programas e ações estabelecidas (Iaupe, 2010e).

O Núcleo de Gestão tem como objetivo primordial coordenar a execução e o funcionamento necessários ao atendimento do previsto nos Contratos de Programa específicos para a prestação dos serviços públicos contratados. Os Núcleos de Gestão são criados conforme necessidade do consórcio de realizar ações específicas por área de interesse (Iaupe, 2010e).

Na área de saúde o Cisape criou o núcleo de gestão chamado Núcleo Intermunicipal de Saúde (NIS), que se caracteriza como elemento fundamental no processo de regionalização da saúde. Com sede no município de Ouricuri, o NIS teve como objetivo estudar e apontar soluções para as políticas públicas de saúde da região e no apoio à gestão dos municípios consorciados (Iaupe, 2010f).

De acordo com o relatório (Iaupe, 2010f) a primeira ação prevista no contrato de programação estabelecido no Consórcio Intermunicipal da Região do Araripe (Cisape) foi a descentralização da administração do Hospital Regional Fernando Bezerra, que passou a ser gerido pelo NIS do Cisape. O processo de transição na administração do hospital regional se iniciou com a assinatura do contrato de programa do Cisape.

Observamos nos relatórios, a exemplo da figura 1, que a estrutura organizacional do Cisape está pautada no modelo burocrático, onde existe a especialização das funções, estrutura complexa, altamente hierarquizada, e divisão de poder a partir de níveis hierárquicos.

Contudo, foram encontrados indícios de que na política organizacional a administração está em fase de transição, ficando evidentes algumas características do gerencialismo na estrutura organizacional, como: esfera de controle reduzida pelo empowerment e competências e autoridade centrada na hierarquia de competências. 
Figura 1

Estrutura organizacional do Cisape

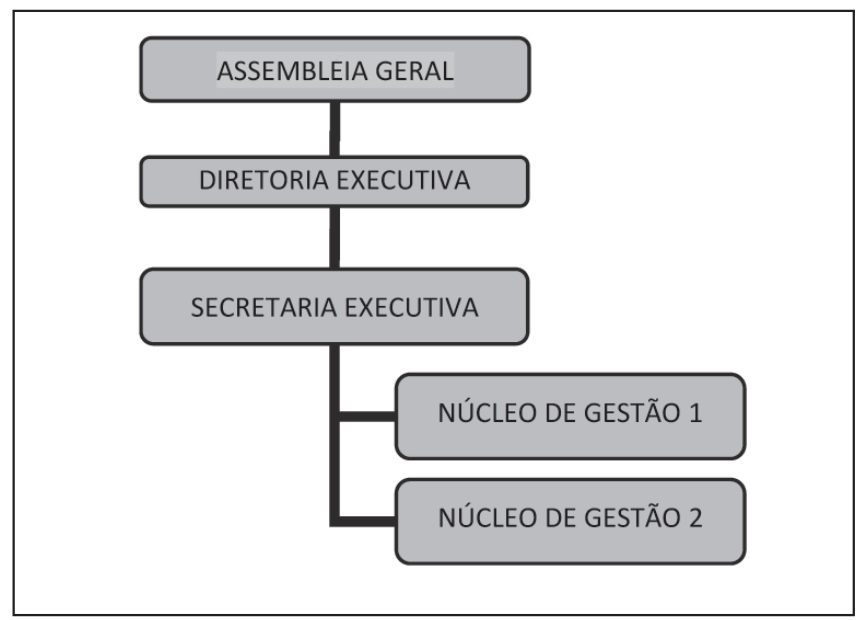

Fonte: Relatório da Gestão Regionalizada, Consorciada e Integrada da Saúde Pública no Estado de Pernambuco/Governo do Estado de Pernambuco (2010).

\subsection{Contrato de programa e contrato de rateio}

O contrato de programa entre SES e Cisape foi assinado em 13 de maio de 2010 na sede da IX Geres. Esse instrumento legal constitui a gestão associada da política regional de atenção à saúde no território do Cisape. Através dele, o estado objetiva oferecer maior resolutividade e melhor qualidade dos serviços de saúde (Iaupe, 2010f).

A partir do contrato de programa é que o Consórcio passa a executar as diversas ações e serviços públicos demandados pela sociedade. O contrato de programa exige uma Programação Pactuada Consorciada (PPC) das demandas locais, baseada nas necessidades reais e no perfil da população.

Para ser aprovado, o contrato de programa do Cisape necessitou da aprovação da Procuradoria-Geral do Estado (PGE). No primeiro momento, a minuta do contrato de programa foi encaminhada pela Secretaria de Saúde do Estado (SES-PE) para análise da PGE, que solicitou da mesma uma cota, que foi respondida pela SES em conjunto com o Iaupe (2010f). No segundo momento, foi solicitada pela PGE à SES uma segunda cota, que também foi respondida pela SES em parceria com o Iaupe (2010f). Após aprovação, o documento foi encaminhado para assinatura dos prefeitos dos 13 municípios consorciados e do estado (Iaupe, 2010f).

A Lei Federal no 11.107, em seu art. $8^{\circ}$, considera que os entes consorciados somente entregarão recursos ao consórcio público mediante contrato de rateio.

O contrato de rateio estabelece as obrigações de prestação de serviços pelos entes consorciados, a forma de transferência total ou parcial dos encargos, de pessoal ou bens necessários ao seu funcionamento. É o instrumento pelo qual devem ser constituídas e reguladas as 
obrigações que um ente da federação, inclusive sua administração indireta, tenha para com outro ente da federação, ou para com consórcio público, no âmbito da prestação de serviços públicos por meio de cooperação federativa.

O contrato de rateio é considerado um instrumento jurídico formal que define as responsabilidades econômico-financeiras por parte de cada consorciado e a forma de repasse de recursos de cada participante, para a realização das despesas do consórcio público. Neste caso, contrato de rateio têm vigência de 12 meses, quando são avaliados para possíveis renovações (Iaupe, 2010d).

No caso do Cisape, o contrato de rateio previu o repasse mensal pelo município-membro para o consórcio, referente à sua cota-parte destinada às despesas de administração e

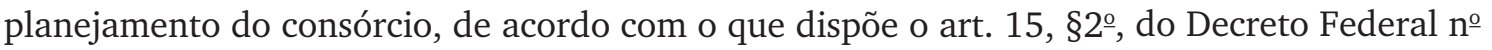
6.017/2007 (Iaupe, 2010b).

\subsection{Gestão financeira e mecanismos de financiamento do NIS-Cisape}

A gestão financeira do consórcio no custeio de suas atividades administrativas é estabelecida por meio de contribuições mensais entre os municípios. Esses valores são definidos através da utilização de critérios populacionais/utilização dos serviços; recursos do SUS, a partir dos sistemas de informações ambulatoriais e hospitalares.

Na Lei no 8.142/1990, os arts. $2^{\circ}$ e 3 ํ dispõem sobre o repasse de recursos do SUS para consórcios, definindo que os municípios podem estabelecer consórcios para execução de ações e serviços de saúde, remanejando, entre si, parcelas de recursos do Fundo Nacional de Saúde (FNS) que são alocados para a cobertura das ações e serviços de saúde a serem implementados pelos municípios, estados e Distrito Federal (Brasil, 1990b).

O contrato de programa é o instrumento utilizado para definir o repasse dos recursos através de convênios com os consórcios e a Secretaria Estadual de Saúde de Pernambuco. O objetivo desses convênios é garantir que o NIS desenvolva atividades que contemplem as metas estabelecidas nesses documentos (Iaupe, 2010d). Neste caso, o Cisape firmou o contrato de rateio com vigência de um ano, quando são avaliados e renovados ou não (Iaupe, 2010d).

No Consórcio do Araripe os relatórios (Iaupe, 2010a, 2010d) demonstram que o Estado participou como financiador e fomentador da gestão regional.

Tem sido uma tendência recente a participação do estado como financiador dos consórcios. Essa participação acontece por meio do repasse de verbas direto ou pela cessão de recursos humanos, materiais, equipamentos, apoio técnico, em aproximadamente $75 \%$ dos consórcios brasileiros (Lima, 2000).

O mecanismo de financiamento se apresenta como aspecto importante para ser analisado entre os modelos gerenciais. No caso do consórcio Cisape esse ponto da abordagem de gestão enfatiza principalmente as dimensões econômico-financeira e a adaptação das recomendações gerencialistas para o setor público. 


\subsection{Controle social do NIS-Cisape}

De acordo com Bravo e Costa (2012), a expressão controle social vem sendo utilizada no Brasil como sinônimo de controle da sociedade civil sobre as ações do Estado, em especial no campo das políticas sociais. Para as autoras, a necessidade de controle social do sistema de saúde brasileiro foi proposta pelo Movimento pela Reforma Sanitária na década de 1980, em um contexto de lutas sociais contra a privatização da medicina previdenciária e a regulação da saúde pelo mercado, colocando-se em discussão a tendência hegemônica de prestação de assistência médica como fonte de lucro. As lutas pela saúde, nesse período, articuladas à redemocratização do país, deram origem à criação do SUS, pela Constituição de 1988, cujas diretrizes incorporam a necessidade de controle social do sistema.

Durante o processo de implantação da Gestão Consorciada na Região do Araripe pernambucano foram realizadas oficinas de sensibilização e planejamento estratégico das equipes municipais (Iaupe, 2010a, 2010b, 2010c). O objetivo dessas oficinas foi realizar um diagnóstico estratégico preliminar dos pontos fortes e fracos do setor saúde de cada município que comporiam o Cisape. Observou-se, a partir dos relatórios (Iaupe, 2010a), uma baixa prioridade dada ao tema controle social, durante as discussões dessas oficinas. A maioria dos $13 \mathrm{mu}-$ nicípios envolvidos não identificou a questão da mobilização/participação social em torno da questão saúde como ponto problemático ou potencialidade no diagnóstico estratégico inicial para implantação do Cisape (Iaupe, 2010c).

Entretanto, um município citou "reuniões mensais do Conselho Municipal de Saúde" como ponto forte em seu diagnóstico estratégico e outro registrou "pouca participação dos Conselhos Municipais de Saúde" como ponto fraco (Iaupe, 2010c).

Embora a participação mais ampla da sociedade civil não tenha ocorrido na elaboração do Plano de Regionalização da Saúde/Cisape, o documento destaca a intenção de mobilizar e engajar a sociedade civil organizada nas discussões e construções referentes à política regional de saúde (Iaupe, 2009b). A principal ação proposta nesse sentido foi a implantação da Assembleia Regional de Conselheiros Municipais de Saúde do Cisape, de caráter fiscalizatório e consultivo (Iaupe, 2009a, 2010c).

A criação dessa instância de controle social estava prevista para o ano de 2010, mas até o final do segundo semestre de 2012 não havia sido criado nenhum espaço de controle social do Cisape.

Nos relatórios analisados evidenciou-se que a participação dos conselhos municipais e a participação social foram incipientes. Existe a orientação para a participação social no nível do discurso, como explicitado nos trechos abaixo:

Quando é dado para a comunidade o conhecimento dos projetos e planos que se pretende, é fundamental que ela possa se posicionar. Com isso, as atividades propostas para que o consórcio possa executá-las contarão com a observação e o olhar fiscalizador da comunidade.

É recomendável o envolvimento da sociedade para que as possibilidades de errar sejam menores e que se possa fazer o que realmente for do interesse do povo. Para tanto se reserva o tempo de atender às solicitações de informações sobre o consórcio público, dando conhecimento da Lei nํㅜ 
11.107/05 e do Decreto-lei no 6.017/07, provocando o debate entre os gestores públicos, prefeitos, secretários, assessores, procuradores, servidores públicos, vereadores, mas também, com setores da sociedade que se entende como importante a sua participação. (Iaupe, 2010d:61)

Promover a interação do Cisape com a população para garantir envolvimento, comprometimento e engajamento dos diversos seguimentos organizados da sociedade (Iaupe, 2010e). "Participação Social - Mobilizar e engajar a sociedade civil organizada nas discussões e construções referentes à política regional de saúde" (Iaupe, 2010f:32).

A realização do Seminário: Oficina de Sensibilização teve a duração de oito horas, envolvendo explanação e debate sobre o tema: "Sensibilização para o planejamento estratégico do NIS-Cisape". A estrutura foi definida e padronizada tendo como público-alvo: o corpo diretivo e gerencial do NIS e atores envolvidos no processo de consolidação do NIS. Esses atores são gestores locais, não citando a participação da sociedade (Iaupe, 2010f).

Porém, a ação se mostrou centralizadora no que se refere ao processo decisório, à organização das instituições políticas e à construção de canais de participação popular.

Esses resultados estão em consonância com estudo realizado por Neves e Ribeiro em 2006, que identificou essa desarticulação dos consórcios de saúde com a sociedade civil organizada.

\subsection{Gestão de pessoas do NIS-Cisape}

A Lei Federal no 11.107, de 2005, preconiza que o Protocolo de Intenções firmado entre entes federados deve prever número, formas de provimento e remuneração dos empregados públicos, bem como os casos de contratação por tempo determinado para atender a necessidade temporária de excepcional interesse público (Brasil, 2005).

No caso do Cisape, o protocolo de intenções reitera a legislação federal e orienta a contratação dos servidores segundo a Consolidação das Leis do Trabalho (CLT) (Iaupe, 2010d), em concordância com o que determina a legislação nacional sobre consórcios públicos. As atividades consorciadas podem ser executadas, também, por servidores cedidos pelos municípios, através de contrato por tempo determinado ou empregados do quadro do consórcio, que são regidos pela legislação trabalhista (Brasil, 2005).

A região do Araripe, com a estruturação do modelo de gestão consorciada, segundo as diretrizes do Governo do Estado, tem sido permeada por uma série de características pósburocráticas na gestão de pessoas, a saber: a constituição de vínculos de trabalho sem estabilidade, flexíveis, precarizando ainda mais a força de trabalho em saúde local. Ressaltamos que a transição na estrutura organizacional mencionada anteriormente influenciou a gestão de pessoas no ambiente interno do Cisape.

Tais conflitos foram identificados desde a fase de implantação do novo modelo de gestão no Araripe pernambucano onde foram realizadas oficinas de sensibilização e planejamento estratégico com as equipes municipais (Iaupe, 2010e). 
As oficinas mostraram que os representantes dos municípios, quando questionados sobre a realidade do seu ambiente interno, foram unânimes em apontar a gestão de pessoas como ponto fraco. Os tópicos mais relevantes foram: grande rotatividade de pessoal, pessoas terceirizadas sem qualificação necessária, falta de estímulo dos trabalhadores, processo seletivo não profissional e pouca integração de pessoas (Iaupe, 2010e).

\section{Considerações finais}

Diante do exposto, pode-se afirmar que o governo do estado utilizou práticas de gestão empregadas no meio empresarial para formular o seu plano político de gestão denominado Todos por Pernambuco - Gestão Democrática e Regionalizada com Foco em Resultados.

A legitimação dessa escolha na política de saúde se expressou na regionalização consorciada no Sertão do Araripe por meio das constantes referências nos documentos analisados ao gerencialismo como racionalidade de gestão e das práticas gerenciais adotadas nessa experiência de gestão intergovernamental do SUS, a exemplo da não criação de uma instância de controle social e da não participação da sociedade civil na formulação e gestão do Cisape. Apresentado, portanto, como uma das principais características das reformas administrativas fundamentadas na nova gestão pública: o insulamento tecnocrático (Andrews, 2010; Neves, 2007).

As críticas a essa racionalidade de gestão vão além do debate sobre os modelos de gestão pública, como se viu; elas remetem à tensão entre dois projetos de política de saúde: o que defende o SUS público e estatal e sua gestão democrático-participativa, e o que defende as parcerias público-privadas e a adoção do gerencialismo na política de saúde, como forma de tornar mais eficiente e efetivo o sistema de saúde.

Embora a formulação e a organização do Cisape sejam apresentadas nos documentos analisados como unicamente técnicas e "não políticas", a busca dessa pretensa neutralidade é outra característica das experiências gerencialistas e representa escolhas políticas ideologicamente conservadoras, pois reduzem o controle e o poder decisório da sociedade sobre as organizações e criam ou fomentam formas mais precárias de contratação da força de trabalho.

Diante dos limites temporais e do objeto deste trabalho, a conclusão do mesmo aponta para a necessidade de novos estudos sobre a gestão pública consorciada, especialmente estudos que se fundamentem na teoria social crítica e que possam analisar as relações de poder que atravessam essa experiência político-gerencial, e pesquisas avaliativas, que verifiquem se o mix da gestão do SUS por meio de consórcios e gerencialismo reduziu ou aprofundou as desigualdades sociais em saúde na região pesquisada.

\section{Referências}

ANDREWS, Christina W. Da década perdida à Reforma Gerencial: 1980-1998. In: ANDREWS, Cristina W. Administração pública no Brasil: breve história política. São Paulo: Unifesp, 2010. p. 85-118. 
BARDIN, Laurence. Análise de conteúdo. São Paulo: Edições 70, 2011. p. 280.

BATISTA, Sinoel et al. O papel dos prefeitos e das prefeitas na criação e na gestão dos consórcios públicos. Brasília, DF: Caixa Econômica Federal, 2011. p. 58-63.

BOTTI, Cristina S. Avaliação do processo de implementação do Consórcio Intermunicipal de Saúde da região do Teles Pires. Dissertação (Mestrado) - Escola Nacional de Saúde Pública, Fundação Oswaldo Cruz, Rio de Janeiro, 2010.

BRASIL. Constituição brasileira 1937. D.O.U. 10.11.1937.

BRASIL. Constituição da República Federativa do Brasil. São Paulo: Atlas, 1988.

BRASIL. Decreto-lei no 6.017, de 17 de janeiro de 2007. Regulamenta a Lei no 11.107, de 06 de abril de 2005, que dispõe sobre as normas gerais de contratação de consórcios públicos. Brasília, 17 de janeiro de 2007.

BRASIL. Decreto-lei no 7.508 de 28 de junho de 2011. Regulamenta a Lei no 8.080, de 19 de setembro de 1990, para dispor sobre a organização do Sistema Único de Saúde — SUS, o planejamento da saúde, a assistência à saúde e a articulação interfederativa, Brasília, 2011.

BRASIL. Lei $n^{\circ}$ 8.080, de 19 de setembro de 1990a. Dispõe sobre as condições para a promoção, proteção e recuperação da saúde, a organização e o funcionamento dos serviços correspondentes e dá outras providências. Diário Oficial da República Federativa do Brasil, Brasília, n. 182, 20 set. 1990.

BRASIL. Lei no 8.142 de 28 de dezembro de 1990b. Dispõe sobre a participação da comunidade na gestão do Sistema Único de Saúde (SUS) e sobre as transferências intragovernamentais de recursos financeiros na área de saúde. Diário Oficial da República Federativa do Brasil, Brasília, 31 dez. 1990.

BRASIL. Lei no 11.107 de 6 de abril de 2005. Dispõe sobre as normas gerais para a União, Estados e os Municípios contratarem consórcios públicos para a realização de objetivos de interesse comum e dá outras providências. Brasília, 6 de abril de 2005.

BRASIL. Portaria nํ5 545 de 20 de maio de 1993. Estabelece normas e procedimentos reguladores do processo de descentralização da gestão das ações e serviços de saúde, através da Norma Operacional Básica, SUS 01/93. Diário Oficial da União, 1993.

BRASIL. Portaria nํㅜ 2.203 de 5 de novembro de 1996. Estabelece normas e procedimentos reguladores do processo de descentralização da gestão das ações e serviços de saúde, através da Norma Operacional Básica, SUS 01/96; Diário Oficial da União, 1996.

BRAVO, Maria I. S.; COSTA, Maria V. Desafios do controle social na atualidade. Revista do Serviço Social e Sociedade, São Paulo, n. 109, p. 126-150, jan./mar. 2012.

BRESSER-PEREIRA, Luiz C.; SPINK, Peter K. (Org.). Reforma do Estado e administração pública gerencial. Rio de Janeiro: FGV, 1998.

FARAH, Marta F. S. Inovação e governo local no Brasil contemporâneo. In: JACOBI, Pedro; PINHO, José Antonio. Inovação no campo da gestão pública local: novos desafios, novos patamares. São Paulo: FGV, 2006. p. 41-76. 
FLEURY, Sonia. Reforma sanitária brasileira: dilemas entre o instituinte e o instituído. Ciência e Saúde Coletiva, Rio de Janeiro, v. 14, n. 3, p. 743-752, 1 maio 2009. Disponível em: <www.scielosp. org/scielo.php? script $=$ sci_arttext\&pid $=$ S1413-81232009000300010\&lang $=$ pt\&tlng $=>$. Acesso em: 31 out. 2012.

IAUPE. Carta Iaupe no 357 - proposta de trabalho. Recife, 2009a. p. 12.

IAUPE. Gestão regionalizada, consorciada e integrada da saúde pública no estado de Pernambuco. Recife, 2010c. p. 44.

IAUPE. Gestão regionalizada, consorciada e integrada da saúde pública no estado de Pernambuco. Recife, 2010d. p. 62.

IAUPE. Gestão regionalizada, consorciada e integrada da saúde pública no estado de Pernambuco. Recife, 2010a. p. 64.

IAUPE. Gestão regionalizada, consorciada e integrada da saúde pública no estado de Pernambuco. Recife, 2010e. p. 78.

IAUPE. Gestão regionalizada, consorciada e integrada da saúde pública no estado de Pernambuco. Recife, 2010g. p. 86.

IAUPE. Gestão regionalizada, consorciada e integrada da saúde pública no estado de Pernambuco. Recife, 2010b. p. 101.

IAUPE. Gestão regionalizada, consorciada e integrada da saúde pública no estado de Pernambuco. Recife, 2010f. p. 169.

IAUPE. Oficinas regionais para construção de consensos da regionalização. Recife, 2009b. p. 19.

IBAÑEZ, Nelson; VECINA NETO, Gonzalo. Modelos de gestão e o SUS. Ciência e Saúde Coletiva, Rio de Janeiro, v. 12, n. suppl.0, p. 1831-1840, nov. 2007. Disponível em: <www.scielosp.org/ scielo.php?script $=$ sci_arttext\&pid $=$ S1413-81232007000700006\&lang $=$ pt\&tlng $=>$. Acesso em: 31 out. 2012.

IPEA. Políticas sociais: acompanhamento e análise. Brasília, DF: Ipea, 2010.

LIMA, Ana Paula G. Os consórcios intermunicipais de saúde e o sistema único de saúde. Dissertação (Mestrado) — Escola Nacional de Saúde Pública, Fundação Oswaldo Cruz, Rio de Janeiro, 1998.

LIMA, Ana Paula G. Os consórcios intermunicipais de saúde e o Sistema Único de Saúde. Cadernos de Saúde Pública, Rio de Janeiro, v. 16, n. 4, p. 985-996, out. 2000. Disponível em: <www.scielosp. org/scielo.php? script $=$ sci_arttext\&pid $=$ S0102-311X2000000400017\&lang $=$ pt\&tlng $=>$. Acesso em: 31 out. 2012.

NEVES, Angela V. Espaços públicos e práticas políticas: os riscos de despolitização da participação da sociedade civil. In: DAGNINO, Evelina; TATAGIBA, Luciana (Org.). Democracia, sociedade civil e participação. Chapecó: Argos, 2007. p. 395-420. 
NEVES, Luiz A.; RIBEIRO, José M. Consórcios de saúde: estudo de caso exitoso. Cadernos de Saúde Pública, Rio de Janeiro, v. 22, n. 10, p. 2207-2217, out. 2006. Disponível em: <www.scielosp.org/ scielo.php?script $=$ sci_arttext\&pid $=$ S0102-311X2006001000027\&lang $=$ pt\&tlng $=>$. Acesso em: 31 out. 2012.

NICOLETTO, Sônia C. S. et al. Consórcios intermunicipais de saúde: o caso do Paraná, Brasil. Cadernos de Saúde Pública, Rio de Janeiro, v. 21, n. 1, p. 2005-38, jan. 2005. Disponível em: <www. scielosp.org/scielo.php?script=sci_arttext\&pid=S0102-311X2005000100004\&lang $=$ pt\&tlng $=>$. Acesso em: 31 out. 2012.

OLIVEIRA, Vanessa E. Municípios cooperando com municípios: relações federativas e consórcios intermunicipais de saúde no estado de São Paulo. São Paulo em Perspectiva, Fundação Seade, v. 22, n. 1, p. 107-122, jan./jun. 2008. Disponível em: <www.seade.gov.br>; <http://www.scielo. br>. Acesso em: 31 out. 2012.

PAIM, Jairnilson S.; TEIXEIRA, Carmen F. Configuração institucional e gestão do Sistema Único de Saúde: problemas e desafios. Ciência e Saúde Coletiva, Rio de Janeiro, v. 12, n. suppl.0, p. 18191829, nov. 2007. Disponível em: <www.scielosp.org/scielo.php?script=sci_arttext\&pid=S141381232007000700005\&lang=pt\&tlng=>. Acesso em: 31 out. 2012.

PAULA, Ana P. P. Administração pública brasileira entre o gerencialismo e a gestão social. Revista de Administração de Empresas, São Paulo, v. 15, n. 1, p. 36-49, jan. 2005. Disponível em: <http:// rae.fgv.br/sites/rae.fgv.br/files/artigos/10.1590_S0034- 5902005000100005.pdf >. Acesso em: 31 out. 2012.

PERNAMBUCO. Todos por Pernambuco - gestão democrática e regionalizada com foco em resultados. 2009. Disponível em: <www.pe.gov.br/programas/todos-por-pernambuco/>. Acesso em: 11 set. 2012.

RIBEIRO, José M. Os consórcios intermunicipais no SUS: parceria e cooperação técnica. Revista Espaço para a Saúde, Londrina, v. 3, n. 3, p. 41-42, maio 1994. Disponível em: <www.ccs.uel.br/ espacoparasaude/index.htm>. Acesso em: 31 out. 2012.

RIBEIRO, José M.; COSTA, Nilson R. Regionalização da assistência à saúde no Brasil: os consórcios municipais no Sistema Único de Saúde (SUS). Revista de Planejamento e Políticas Públicas, Rio de Janeiro. n. 22, p. 173-220, dez. 2000.

RIBEIRO, Wladimir A. Cooperação federativa e a Lei de Consórcios Públicos. Brasília, DF: Confederação Nacional dos Municípios, 2007.

ROCHA, Carlos A.; FARIA, Cristina A. Cooperação intermunicipal, reterritorialização da gestão pública e provisão de bens e serviços sociais no Brasil contemporâneo: experiência dos consórcios de saúde em Minas Gerais. In: ENCONTRO NACIONAL DA ABCP, 4., 2004, Rio de Janeiro.

SANO, Hironobu. Federalismo brasileiro: tendências e desafios do associativismo territorial. In: CONGRESSO NACIONAL DE CONSÓRCIOS DE ENTES FEDERADOS EM SAÚDE, I, 2010, Belo Horizonte. Anais do I Congresso Nacional de Consórcios de Entes Federados em Saúde. Belo Horizonte: 
Governo de Minas Gerais, 2010. p. 1-2. Disponível em: <www.congressoconsorciopublico.com.br/ apresentacoes/ap6.pdf>. Acesso em: 28 jan. 2012.

SCHNEIDER, Anamaria C. Cooperação municipal? Um estudo sobre o consórcio de saúde da Região do Médio Paraíba do Rio de Janeiro. Tese (doutorado) — Instituto de Medicina Social, Universidade do Estado do Rio de Janeiro, Rio de Janeiro, 2005.

SIMÕES, Breno H. A. P. Lei de consórcios públicos: aplicabilidade e desafios para a gestão do SUS. In: CONGRESSO CONSAD DE GESTÃO PÚBLICA, IV, 2010, Brasília. Anais... Brasília, 25 a 27 de maio de 2010. Painel 52: Os consórcios intermunicipais de saúde: um enfoque institucional, jurídico e espacial. p. 27

VIANA, Ana L. D. et al. Saúde, desenvolvimento e inovação tecnológica: nova perspectiva de abordagem e de investigação. Lua Nova, São Paulo, n. 83, p. 41-77, 2011.

YIN, Robert K. Estudo de caso: planejamento e métodos. 3. ed. Porto Alegre: Bookman, 2005.

Jadson Mendonça Galindo é especialista em saúde pública e professor preceptor do curso de medicina da Universidade Federal de Pernambuco (UFPE). E-mail: jadsonmg@yahoo.com.br.

Joselma Cavalcanti Cordeiro é doutora em saúde pública e professora adjunta da Faculdade de Ciências Médicas da Universidade de Pernambuco (UPE).E-mail: cordeirojc@hotmail.com.

Renata Alves Gomes Villani é mestre em saúde pública e analista em saúde da Secretaria Estadual de Saúde de Pernambuco (SES-PE).E-mail: rgomes.villani@gmail.com.

Evandro Alves Barbosa Filho é doutorando do programa de pós-graduação em serviço social da Universidade Federal de Pernambuco (UFPE). E-mail: evealves85@yahoo.com.br.

Cecile Soriano Rodrigues é doutora em epidemiologia e saúde pública pela Universidade de Londres e professora adjunta do Núcleo Integrado de Saúde Coletiva da Universidade de Pernambuco (Nisc/UPE). E-mail: cecile_rodrigues@hotmail.com. 